\title{
Elucidation of the Presence and Location of $t$-Boc Protecting Groups in Amines and Dipeptides Using On-Column H/D Exchange HPLC/ESI/MS
}

\author{
Christian Wolf and Cristina N. Villalobos \\ Chemistry Department, Georgetown University, Washington, District of Columbia, USA \\ Paul G. Cummings, Sonya Kennedy-Gabb, Mark A. Olsen, \\ and Gudrun Trescher \\ Chemical Development, GlaxoSmithKline Pharmaceuticals, King of Prussia, Pennsylvania, USA
}

\begin{abstract}
High performance liquid chromatography/mass spectrometry (HPLC/MS) has become a widely used technique for routine analysis of pharmaceutical compounds. The constant search for new drugs requires the development of time-efficient methods that can be employed in high-throughput screening of combinatorial libraries of a variety of compounds, including amines and peptides. Conventional HPLC/MS is a powerful technique that can easily be automated and is suitable for comprehensive screening purposes. However, the unequivocal determination of the presence and location of important carbamoyl protecting groups of amines is often elusive because of their inherent instability under MS conditions. In this study, the use of on-column H/D exchange HPLC/ESI/MS for structure elucidation of $t$-Boc protecting groups which can often not be detected by MS because of facile McLafferty rearrangement has been examined. We demonstrate that employing a deuterated mobile phase in HPLC/MS analysis provides a convenient tool for the determination of the absence or presence of $t$-Boc protecting groups in amines and peptides. (J Am Soc Mass Spectrom 2005, 16, 553-564) @ 2005 American Society for Mass Spectrometry
\end{abstract}

A fast and unequivocal identification of the presence and location of $t$-Boc protecting groups plays an essential role in routine analysis and high-throughput screening of combinatorial libraries of complex amines or peptides. The widespread use of the $t$-Boc protecting group in organic synthesis and in particular in peptide chemistry requires a reliable method for the fast determination of its absence or presence in amines and amino acids. Although HPLC/MS is a very powerful technique for the determination of the structure of organic compounds, information about the labile $t$-Boc functionality is often elusive because of the fast McLafferty rearrangement of the tert-butyl carbamoyl group. For example, $t$-Boc protected amino alcohol 1 readily undergoes McLafferty rearrangement under standard MS conditions to form fragment 2 exhibiting $m / z$ 152, Scheme 1 [1]. This fragmentation pathway may proceed via a labile intermediate carbamoyl acid intermediate 3, which easily eliminates carbon dioxide and is therefore often not

Published online February 23, 2005

Address reprint requests to Professor C. Wolf, Department of Chemistry, Georgetown University, 37th and O Streets, Washington, DC 20057, USA.

E-mail: cw27@georgetown.edu observed. Because the unprotected amino alcohol 4 affords fragment $\mathbf{2}$ after ionization in the MS detector, mass spectrometry does not provide a means to differentiate between 1 and 4, i.e., the determination of the presence of the $t$-Boc group requires isolation and further spectroscopic analysis or the use of reference samples for a time-consuming comparison of HPLC retention times which is unsuitable for high-throughput screening.

Structure elucidation by mass spectrometry has become increasingly successful through the introduction of chemical ionization with $\mathrm{ND}_{3}, \mathrm{D}_{2} \mathrm{O}$, and $\mathrm{CD}_{3} \mathrm{OD}$ for exchange of hydrogen for deuterium of organic compounds in the gas phase [2]. This technique can be applied to H/D exchange MS analysis of various classes of compounds including alcohols, carboxylic acids, amines, amides, and thiols [3]. It has also been shown that hydrogens bonded to carbon atoms in aromatic compounds can be replaced by deuterium in the gas phase [4]. The coupling of HPLC and mass spectrometry combines a powerful separation technique with the sensitive and informative MS detection mode, which opens a new venue for H/D exchange MS analysis of complex mixtures containing polar compounds. To date, various MS techniques including chemical ionization detection mass spectrometry (CI/MS) [5], fast atom 

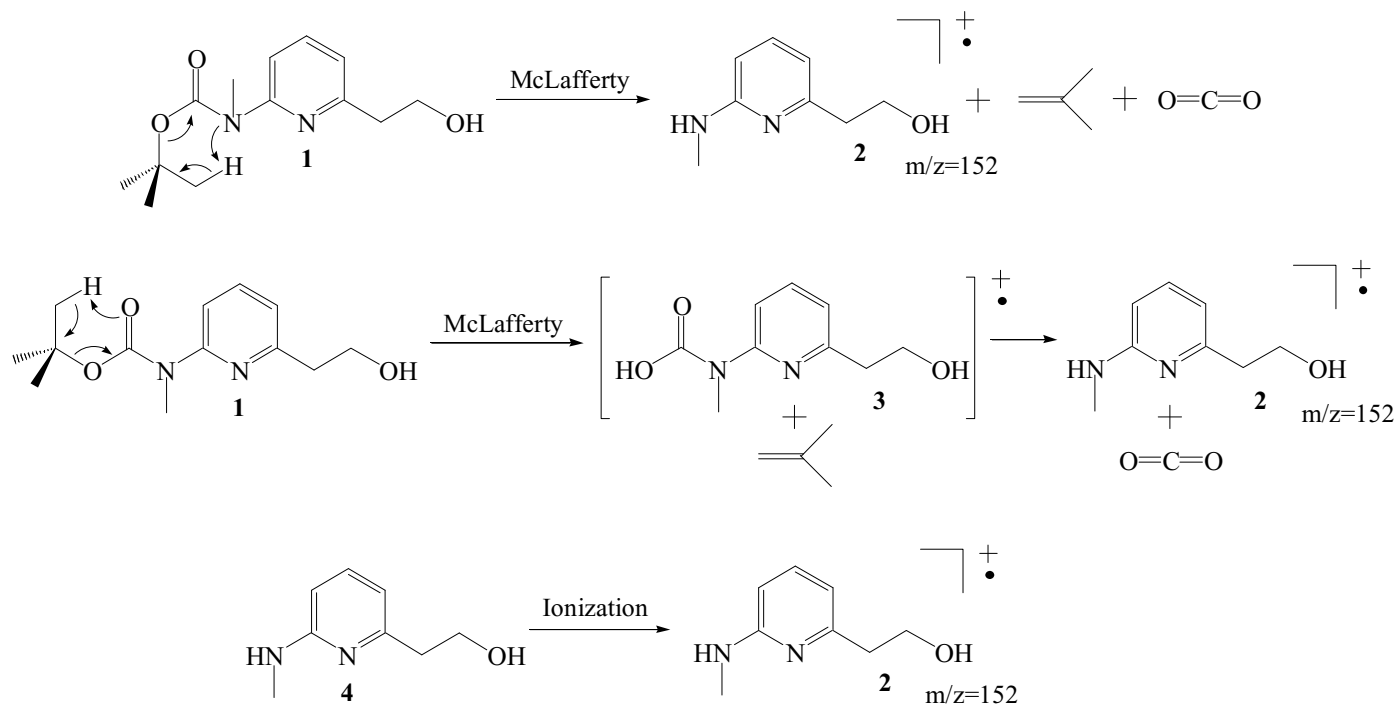

Scheme 1. McLafferty rearrangement of $\mathbf{1}$ and ionization of $\mathbf{4}$ under MS conditions.

bombardment mass spectrometry (FAB/MS) [6], liquid secondary ion mass spectrometry (LSI/MS) [7], electrospray mass spectrometry (ESI/MS) [8], and thermospray mass spectrometry (TSP/MS) [9] utilizing a deuterated mobile phase or matrix have been reported. Deuterated mobile phase HPLC has also successfully been combined with NMR [10] and IR spectroscopy [11].

We report herein the use of deuterated mobile phase HPLC/MS for the fast elucidation of the absence or presence of $t$-Boc protection groups in amines and peptides. Employing on-line H/D exchange HPLC/ ESI/MS in the analysis of aminopyridines and 16 dipeptides, both $t$-Boc protected and unprotected, we found that the presence and position of this labile protecting group as well as the amino sequence can readily be identified.

\section{Experimental}

All dipeptides studied herein were synthesized from commercially available $t$-Boc protected amino acids and amino acid methyl esters using PyBop (benzotriazole1-yl-oxy-tris-pyrrolidino-phosphonium hexafluorophosphate) as the coupling agent [12]. Hydrolysis under mild acidic conditions allowed selective cleavage of the $t$-Boc group to afford the corresponding unprotected dipeptides. All samples were analyzed using an Agilent (Palo Alto, CA) or HP/Bruker (Billerica, MA) ion trap mass spectrometer equipped with Agilent 1100 HPLC systems. The replacement of a nondeuterated with a deuterated mobile phase can cause minor peak shifts. It should be noted that differences in elution times exceeding $0.1 \mathrm{~min}$. observed with some of the samples studied are not a consequence of employing a deuterated mobile phase. In these cases, the sample was analyzed on two instruments with different voids, i.e., the change in retention time is not inherent to the HPLC method used but due to different instrumental setups. The samples were evaluated by flow injection analysis (FIA) and HPLC/ESI/MS. The MS data were collected using in-source CID (collisionally-induced dissociation), which may be enhanced by varying the potential between the skimmer and the capillary exit to increase
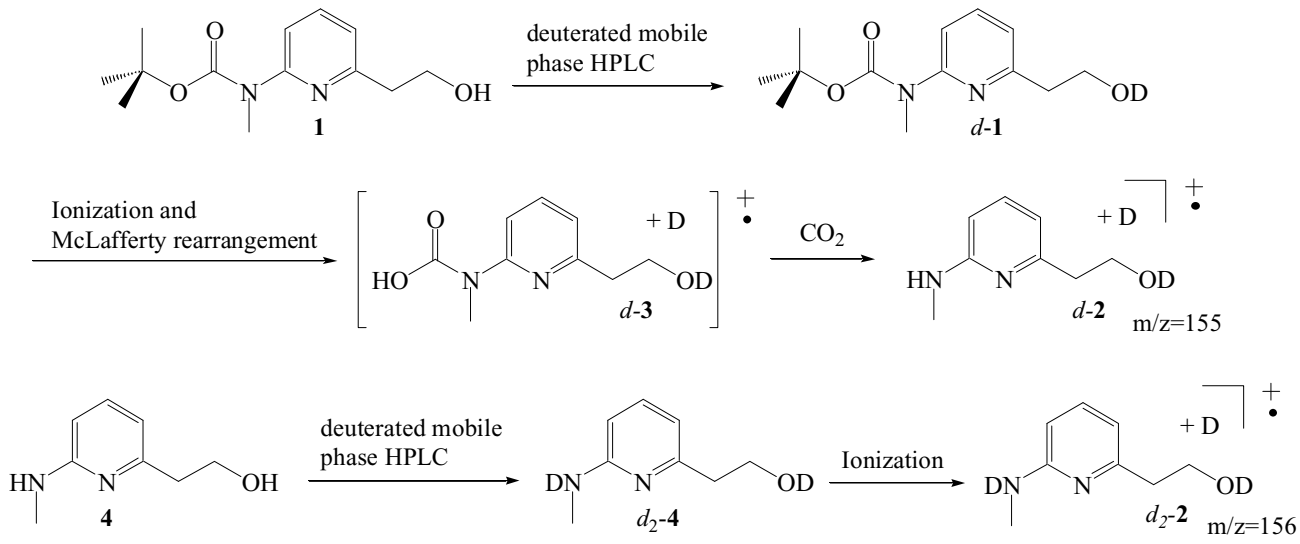

Scheme 2. McLafferty rearrangement of $\mathbf{1}$ and ionization of 4 using deuterated mobile phase $\mathrm{HPLC} / \mathrm{MS}$. 


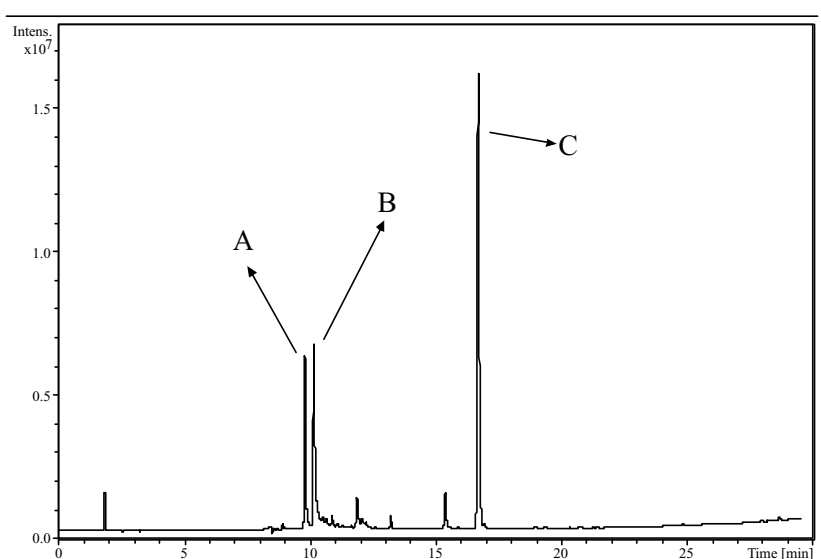

Figure 1. HPLC separation of a mixture of 3 unknown aminopyridines.

or decrease the level of fragmentation. The scan range was 50-850 Da. The capillary exit voltage was set at $4000 \mathrm{~V}$ and the fragmentor voltage was $80 \mathrm{~V}$. The drying gas temperature was $350^{\circ} \mathrm{C}$ and the flow was 12 $\mathrm{L} / \mathrm{min}$. Nebulizer pressure was set at 60 psi. HPLC separation of dipeptides 5-20 was performed using a Waters YMC ODS AM column $(4.6 \times 250 \mathrm{~mm}, 5 \mathrm{~mm})$ and a standard linear gradient over $40 \mathrm{~min}$ starting from $95 \% / 5 \% / 0.1 \%$ to $5 \% / 95 \% / 0.1 \%$ water/acetonitrile/TFA at a flow rate of $1 \mathrm{~mL} / \mathrm{min}$ at ambient temperature. The deuterium exchange experiments were performed using identical conditions replacing water and TFA with deuterium oxide and d-TFA, respectively, ${ }^{\circ}$ as $^{\circ}$ has $^{\circ}$ previously $^{\circ}$ been $^{\circ}$ described $^{\circ}[7]$.

\section{Results and Discussion}

We assumed that on-line H/D exchange HPLC/ ESI/MS would allow differentiation between analytes 1 and $\mathbf{4}$ and derivatives thereof. Employing a deuterated mobile phase in HPLC should afford complete deuterium exchange for molecules containing unprotected amino functions such as $\mathbf{4}$, whereas protected amines such as $\mathbf{1}$ can not undergo proton/deuterium exchange, Scheme 2. During fragmentation amines carrying a $t$-Boc group will undergo a McLafferty rearrangement transferring a hydrogen from a methyl group of the $t$-Boc moiety to the amino function or to the carbonyl oxygen forming an intermediate carbamoyl acid. The protection of $\mathbf{1}$ thus prevents incorporation of deuterium into the amino group during chromatography. As a result, using a deuterated mobile phase in LC/MS analysis affords distinguishable MS fragments $d-2$ and $d_{2}-2$ corresponding to 1 and 4 , respectively.

Our on-column H/D exchange HPLC/ESI/MS strategy was first utilized for the analysis of a three component ${ }^{\circ}$ mixture containing ${ }^{\circ}$ unknown aminopyridines, ${ }^{\circ}$ Figure ${ }^{\circ} 1 .^{\circ}$ Comparison ${ }^{\circ}$ of $^{\circ}$ the ${ }^{\circ}$ mass $^{\circ}$ spectra ${ }^{\circ}$ obtained ${ }^{\circ}$ by $^{\circ} \mathrm{MS}$ following nondeuterated and deuterated mobile phase HPLC gave invaluable information for structure elucidation ${ }^{\circ}$ of $^{\circ}$ each $^{\circ}$ peak. $^{\circ}\left(\right.$ Figure $\left.^{\circ} 2\right)$
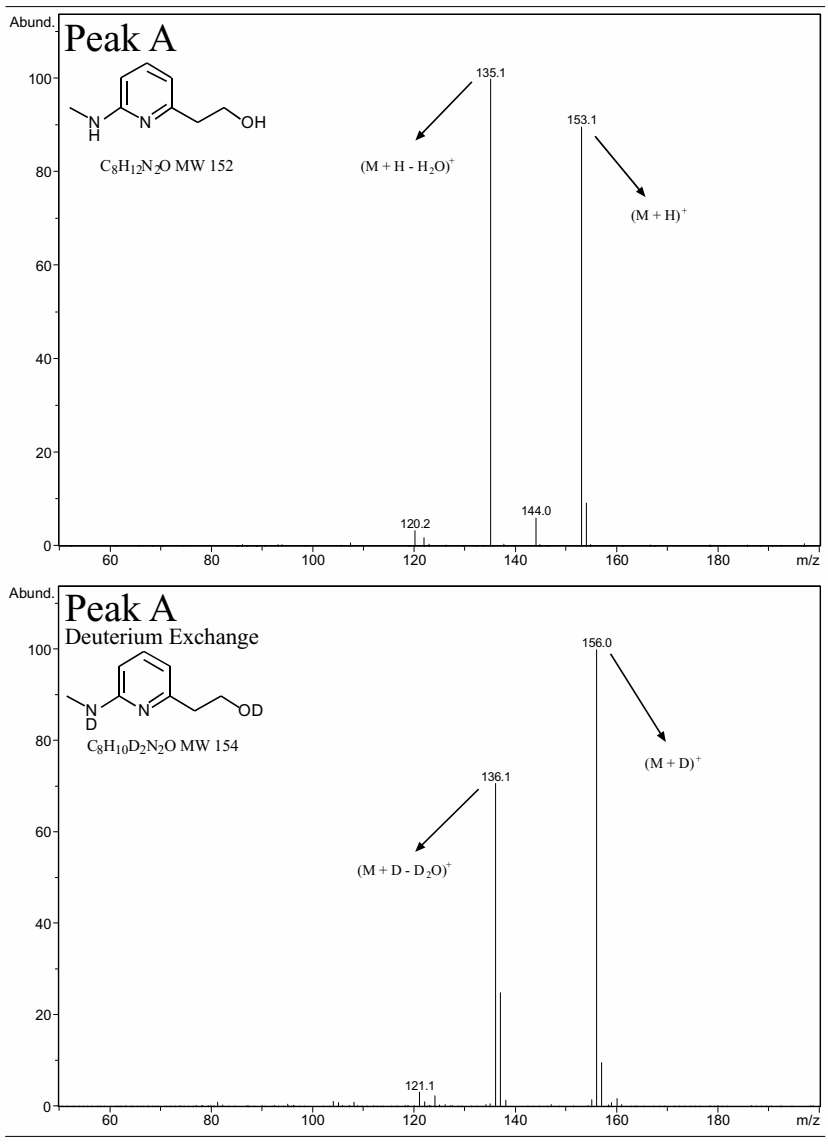

Figure 2. ESI mass spectrum of Peak A. HPLC was performed on a YMC ODS AM column using $\mathrm{CH}_{3} \mathrm{CN} / \mathrm{H}_{2} \mathrm{O} / \mathrm{CH}_{3} \mathrm{CO}_{2} \mathrm{H}$ (top) and $\mathrm{CH}_{3} \mathrm{CN} / \mathrm{D}_{2} \mathrm{O} / \mathrm{CH}_{3} \mathrm{CO}_{2} \mathrm{D}$ (bottom) as the mobile phase.

Peak A does not carry any protecting groups on its amino or alcohol functions and affords a $(\mathrm{M}+\mathrm{H})^{+}$ion signal at $m / z 153$ and an ion fragment at $m / z$ 135, which can be attributed to elimination of water. The deuterium exchange data show the corresponding signals at $\mathrm{m} / \mathrm{z} 136$ and 156 and thus prove the presence of two exchangeable protons, which is consistent with the proposed structure. Since H/D back-exchange is common with amines, a signal at $m / z 136\left(\mathrm{M}+\mathrm{D}-\mathrm{D}_{2} \mathrm{O}\right)^{+}$ and $m / z 137(\mathbf{M}+\mathbf{D}-\mathrm{HOD})^{+}$is observed. The mass spectrum obtained for Peak $B$ by conventional HPLC/MS is misleading because the data suggest a molecular weight of $166 \mathrm{Da}$ according to the $(\mathrm{M}+\mathrm{H})^{+}$ ion $^{\circ}$ signal $^{\circ}{ }^{\circ} \mathrm{m} / \mathrm{z} 167,{ }^{\circ}$ Figure 3 . ${ }^{\circ}$ However, ${ }^{\circ}$ the ${ }^{\circ}$ deuterated mobile phase experiment reveals a $(\mathrm{M}+\mathrm{D})^{+}$ion signal at $m / z 169$ indicating the presence of only one exchangeable hydrogen which can be attributed to the carboxylic acid function. [On-column H/D exchange HPLC/ ESI/MS analysis using a sample treated with diazomethane for selective methylation of the free carboxylic acid group provided further evidence for this asumption.] By contrast, the secondary amino function does not undergo H/D exchange because it carries a $t$-Boc group. The hydrogen attached to the amino group 

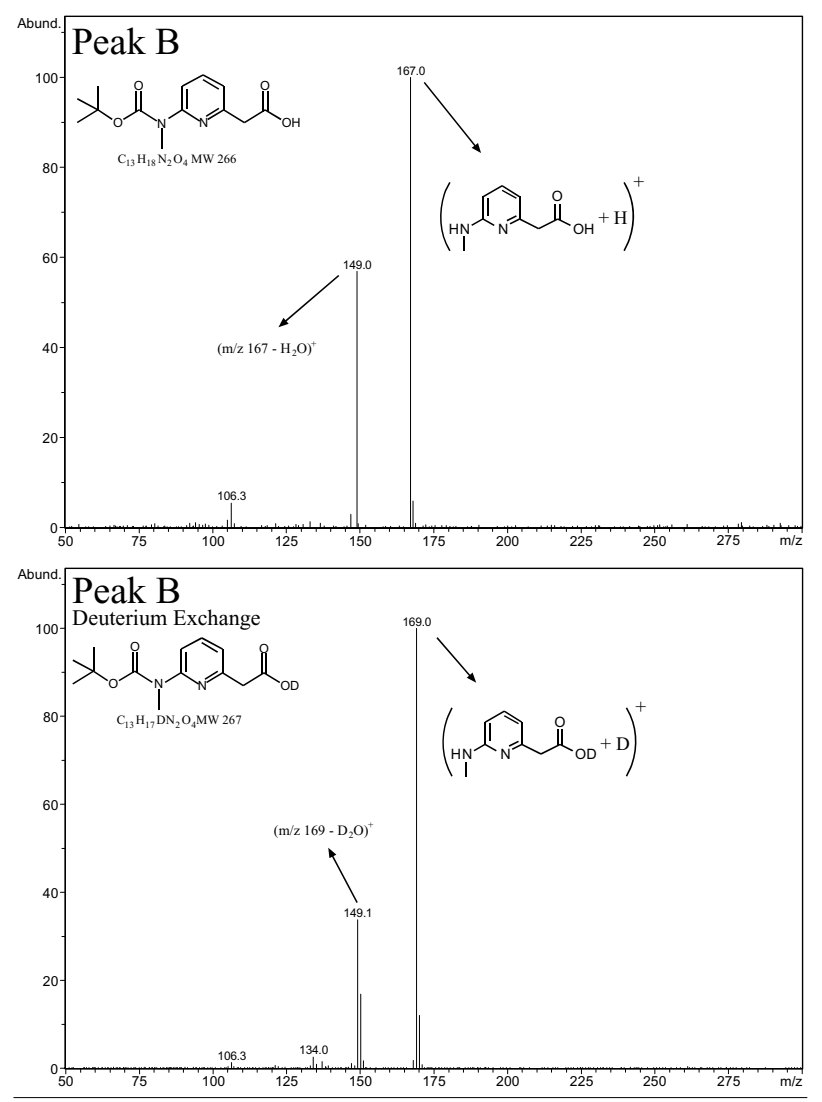

Figure 3. ESI mass spectrum of Peak B. HPLC was performed on a YMC ODS AM column using $\mathrm{CH}_{3} \mathrm{CN} / \mathrm{H}_{2} \mathrm{O} / \mathrm{CH}_{3} \mathrm{CO}_{2} \mathrm{H}$ (top) and $\mathrm{CH}_{3} \mathrm{CN} / \mathrm{D}_{2} \mathrm{O} / \mathrm{CH}_{3} \mathrm{CO}_{2} \mathrm{D}$ (bottom) as the mobile phase.

in the major fragment is a consequence of intramolecular hydrogen transfer through McLafferty rearrangement. Due to H/D back-exchange, a signal at $\mathrm{m} / \mathrm{z} 150$ $(\mathrm{M}+\mathrm{D}-\mathrm{HOD})^{+}$is observed. The deuterium exchange MS data clearly reveal the presence and position of the $t$-Boc group even though the molecular ion or the corresponding carbamoyl acid fragment, which would be indicative of a McLafferty rearrangement, can not be observed.

Routine analysis of the mass spectrum obtained for Peak $C$ obtained with a nondeuterated mobile phase indicates the presence of a carboxylic acid with a molecular weight of $166 \mathrm{Da}$, which would be in accordance with a $(\mathrm{M}+\mathrm{H})^{+}$molecular ion signal at $m / z 167$, Figure $4^{\circ}$ (top ${ }^{\circ}$ panel). ${ }^{\circ}\left[\right.$ The $^{\circ}$ shown ${ }^{\circ}$ carbamoyl ${ }^{\circ}$ acid ${ }^{\circ}$ exhibiting a molecular weight of $166 \mathrm{Da}$ would not be stable during HPLC analysis. Accordingly, one would predict the presence of a carboxylic acid isomer, e.g., 2-(6methylamino-2-pyridyl)acetic acid.] However, the corresponding ion signal following $\mathrm{H} / \mathrm{D}$ exchange is observed at $\mathrm{m} / \mathrm{z} 168$ and suggests that exchangeable hydrogens are not present in this molecule. The detected fragment must therefore be a consequence of a McLafferty rearrangement of a $t$-Boc protected tertiary amine, which does not undergo H/D exchange. Assuming an intramolecular hydrogen transfer from a $t$-Boc
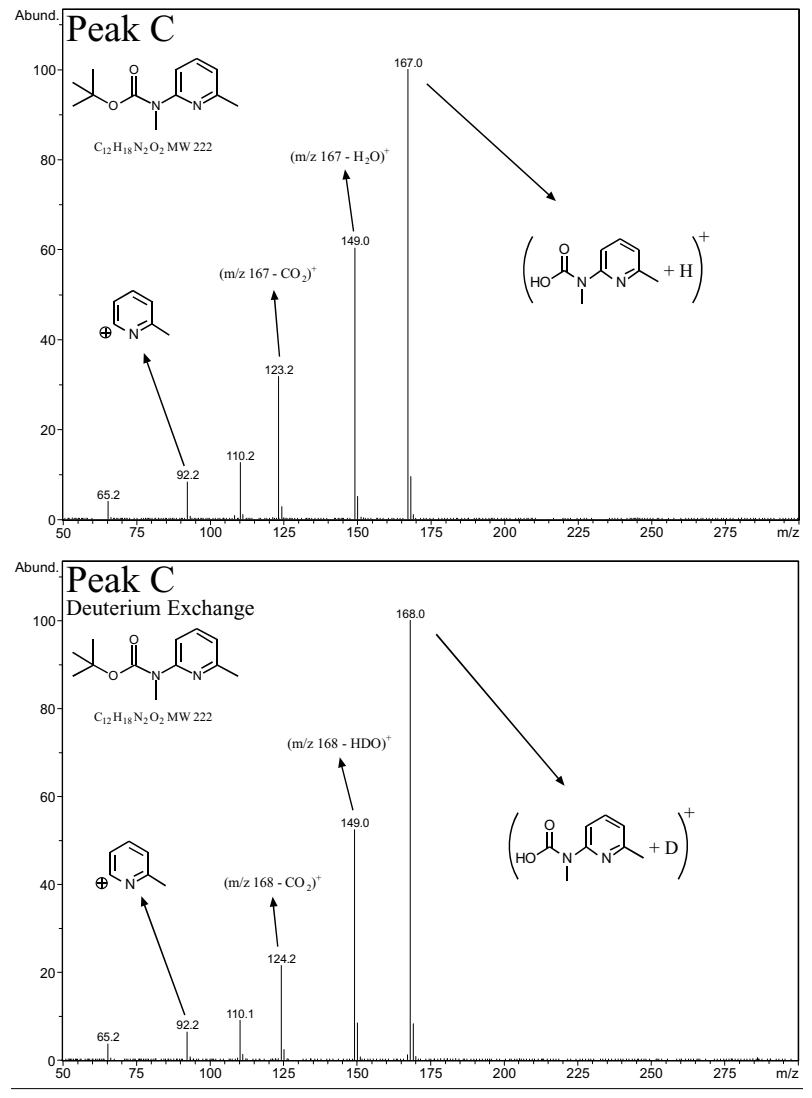

Figure 4. ESI mass spectrum of Peak C. HPLC was performed on a YMC ODS AM column using $\mathrm{CH}_{3} \mathrm{CN} / \mathrm{H}_{2} \mathrm{O} / \mathrm{CH}_{3} \mathrm{CO}_{2} \mathrm{H}$ (top) and $\mathrm{CH}_{3} \mathrm{CN} / \mathrm{D}_{2} \mathrm{O} / \mathrm{CH}_{3} \mathrm{CO}_{2} \mathrm{D}$ (bottom) as the mobile phase.

group to a carbonyl oxygen, the signals exhibiting $\mathrm{m} / \mathrm{z}$ 167 and 168, respectively, can be assigned to a carbamoyl acid fragment generated under MS conditions after chromatographic separation.

We decided to prepare sixteen representative dipeptides to further study the use of our on-column H/D exchange HPLC/ESI/MS method for structure elucidation of $N$-terminal $t$-Boc-protected dipeptides and their unprotected ${ }^{\circ}$ analogs, ${ }^{\circ}$ Figure ${ }^{\circ}$.

Employing a deuterated mobile phase in the chromatographic separation of dipeptides 5-20 should result in complete proton/deuterium exchange for all protons attached to a heteroatom. At the $N$-terminus, the unprotected dipeptides $5,7,9,13,15,17$, and 19 can exchange two protons (but only one proton in dipeptide 11), whereas the $t$-Boc protected derivatives $6,8, \mathbf{1 0}, \mathbf{1 4}$, 16, 18, and 20 can only exchange one proton for deuterium (none in 12). In addition, the amide protons and the proton of the Z-carbamate group of the ornithine derivatives $\mathbf{1 5}$ and $\mathbf{1 6}$ will also be exchanged. In accordance with the results obtained with aminopyridines, we expected that comparison of mass spectral data obtained in conjunction with nondeuterated and deuterated HPLC would provide clear evidence of the presence and position of $t$-Boc groups.

Comparison of the HPLC/CID/MS spectral data 


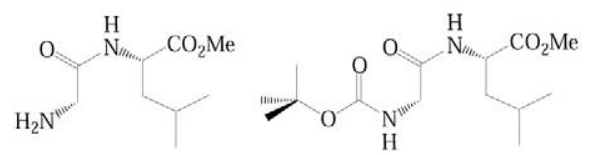

Gly-(S)-Leu-OMe, 5

$N-t$-Boc-Gly-(S)-Leu-OMe, 6
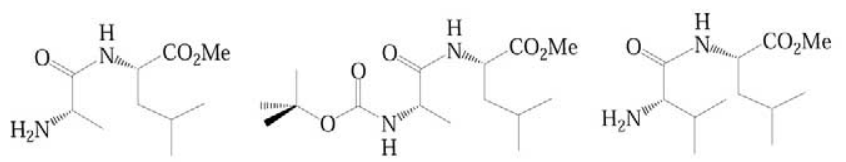

(S)-Ala-(S)-Leu-OMe, 7

$N$-t-Boc-(S)-Ala-(S)-Leu-OMe, 8

(S)-Val-(S)-Leu-OMe, 9

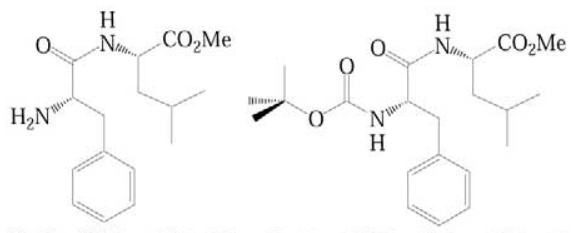

(S)-Phe-(S)-Leu-OMe, $13 \quad N-t$-Boc-(S)-Phe-(S)-Leu-OMe, 14

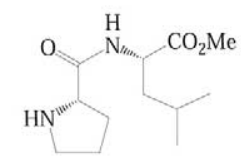

(S)-Pro-(S)-Leu-OMe, 11

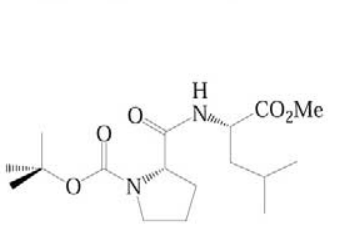

$N-t$-Boc-(S)-Pro-(S)-Leu-OMe, 12

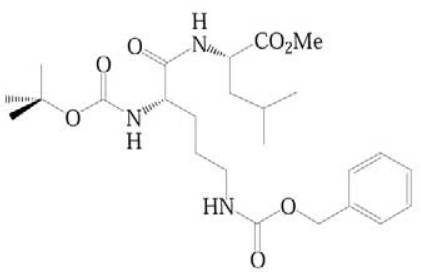

$N-\alpha-t$-Boc- $N-\delta-Z-(S)-O r n-(S)-L e u-O M e, 16$

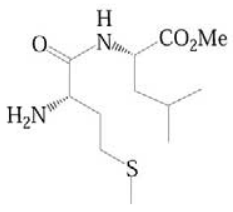

(S)-Met-(S)-Leu-OMe, 17

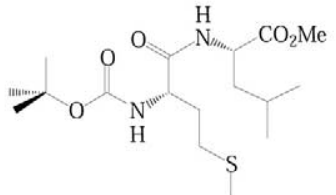

$N-t$-Boc-(S)-Met-(S)-Leu-OMe, 18

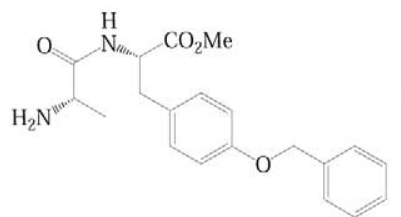

(S)-Ala-O-Bn-(S)-Tyr-OMe, 19

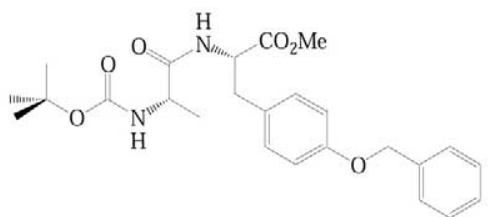

$N$ - $t$-Boc-(S)-Ala- $O$-Bn-(S)-Tyr-OMe, 20

Figure 5. Structure of dipeptides 5-20.

obtained for dipeptide 5 with and without a deuterated mobile phase reveals the presence of three exchangeable ${ }^{\circ}$ protons, ${ }^{\circ}$ Figures $^{\circ} 6^{\circ}$ and ${ }^{\circ} 7 .^{\circ}$ The $^{\circ}$ molecular ${ }^{\circ}$ ion ${ }^{\circ}$ is easily detected by conventional MS analysis as its $(\mathrm{M}+$ $\mathrm{H})^{+}$or $(\mathrm{M}+\mathrm{Na})^{+}$signal respectively at $\mathrm{m} / \mathrm{z} 203$ and
225. Deuterated mobile phase HPLC/MS affords the corresponding strong signals at $m / z 207\left(\mathrm{~d}_{3}-\mathrm{M}+\mathrm{D}\right)^{+}$ and $228\left(\mathrm{~d}_{3}-\mathrm{M}+\mathrm{Na}\right)^{+}$. Because of the low stability of $t$-Boc groups discussed above, on-line $\mathrm{H} / \mathrm{D}$ exchange MS data are necessary to clearly prove the absence of a

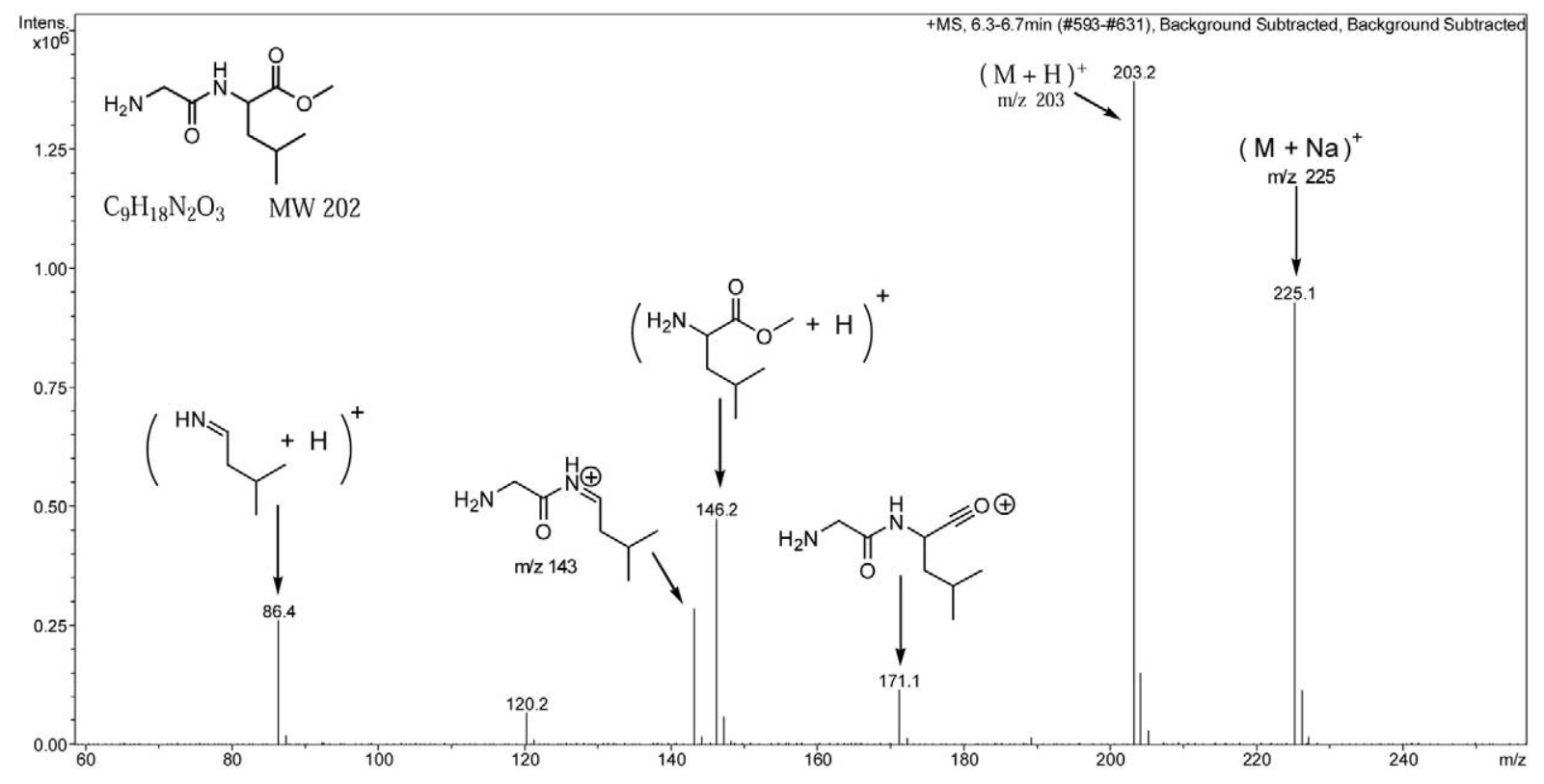

Figure 6. HPLC/CID/MS data of dipeptide 5 using a nondeuterated mobile phase. 


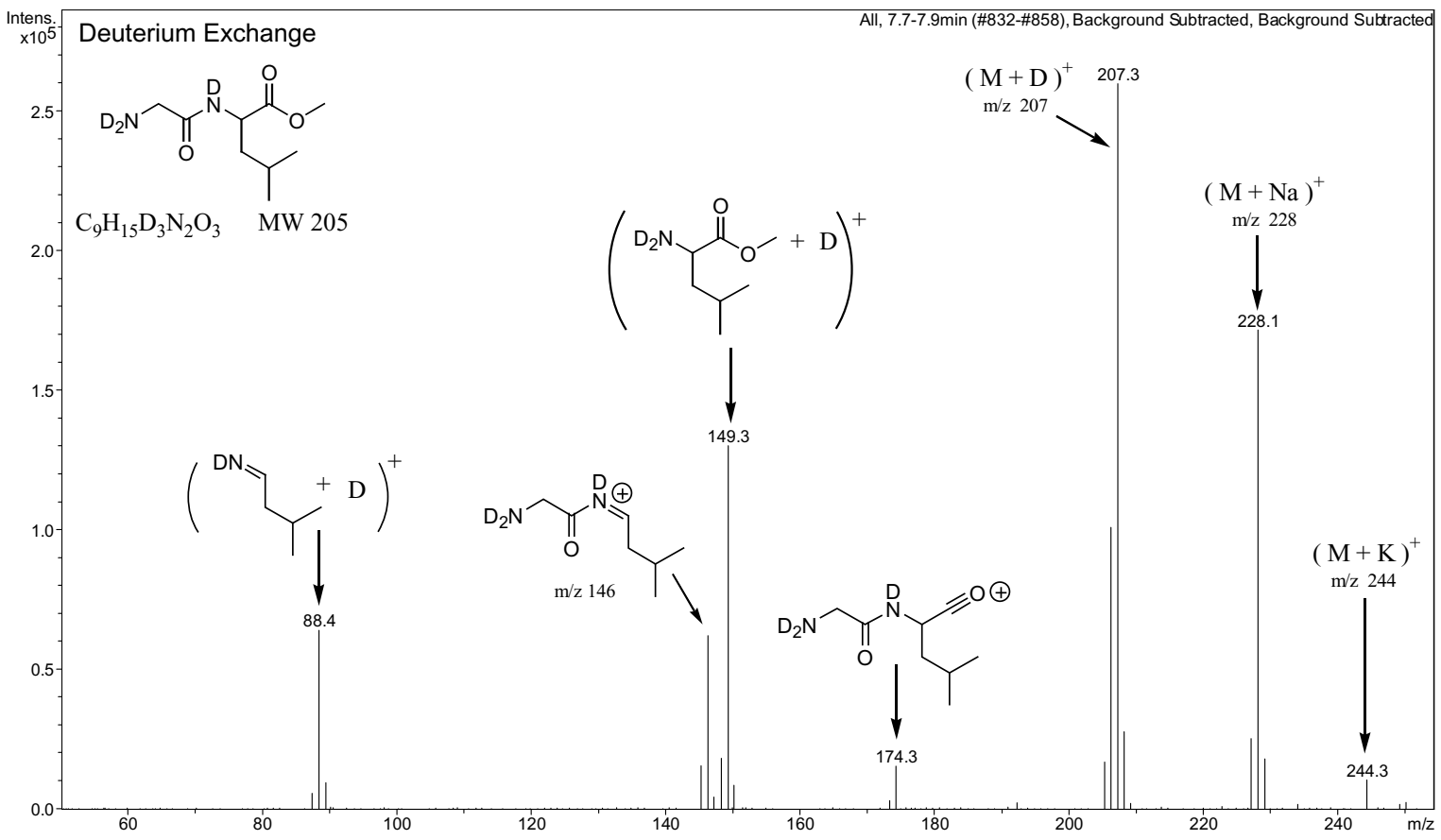

Figure 7. HPLC/CID/MS data of dipeptide 5 using a deuterated mobile phase.

t-Boc group in $\mathbf{5}$ and also allow one to exclude possibly coeluting $t$-Boc-protected impurities.

The MS data of Dipeptide 6 show that one $t$-Boc group $^{\circ}$ is ${ }^{\circ}$ incorporated ${ }^{\circ}$ into ${ }^{\circ}$ the ${ }^{\circ} N$-terminus, ${ }^{\circ}$ Figures ${ }^{\circ} 8$ and $^{\circ}{ }^{\circ} .^{\circ}$ This $^{\circ}$ dipeptide $^{\circ}$ affords $^{\circ}$ two $^{\circ}$ exchangeable $^{\circ}$ pro- $^{\circ}$ tons, one on the $t$-Boc protected amino function and one attached to the peptide bond. As the molecule fragments, the $t$-Boc protected amine acquires an additional hydrogen via a McLafferty rearrangement. While conventional HPLC/MS data would also indicate the presence of one $t$-Boc group because of the $(\mathrm{M}+\mathrm{Na})^{+}$ion signal at $m / z$ 325, the deuterated mobile phase HPLC/MS approach allows one to exclude the presence of additional carbamate functions. It should be noted that the MS data of 6 obtained using a nondeuterated mobile phase in the preceding HPLC separation contain

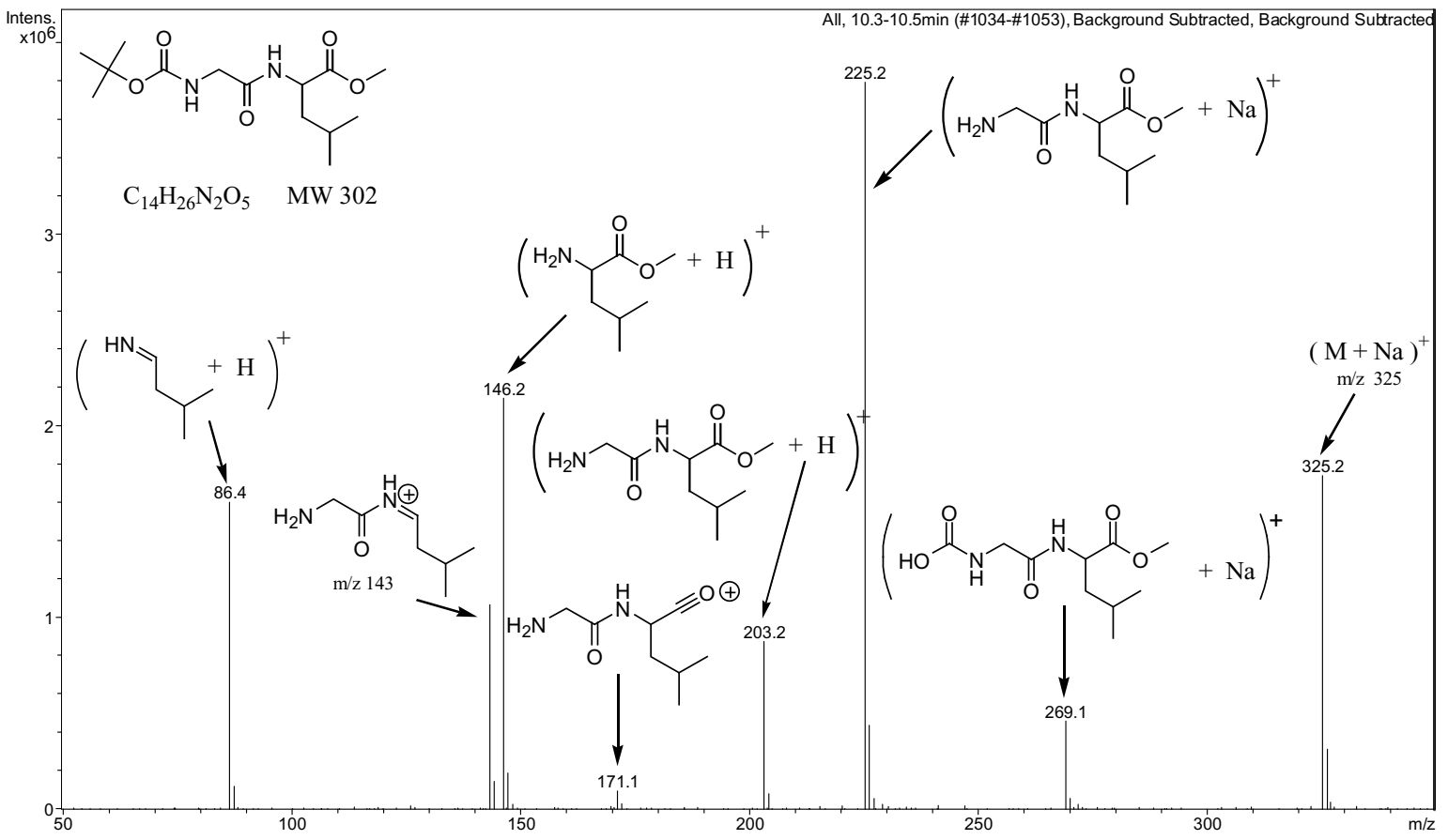

Figure 8. HPLC/CID/MS data of dipeptide 6 using a nondeuterated mobile phase. 


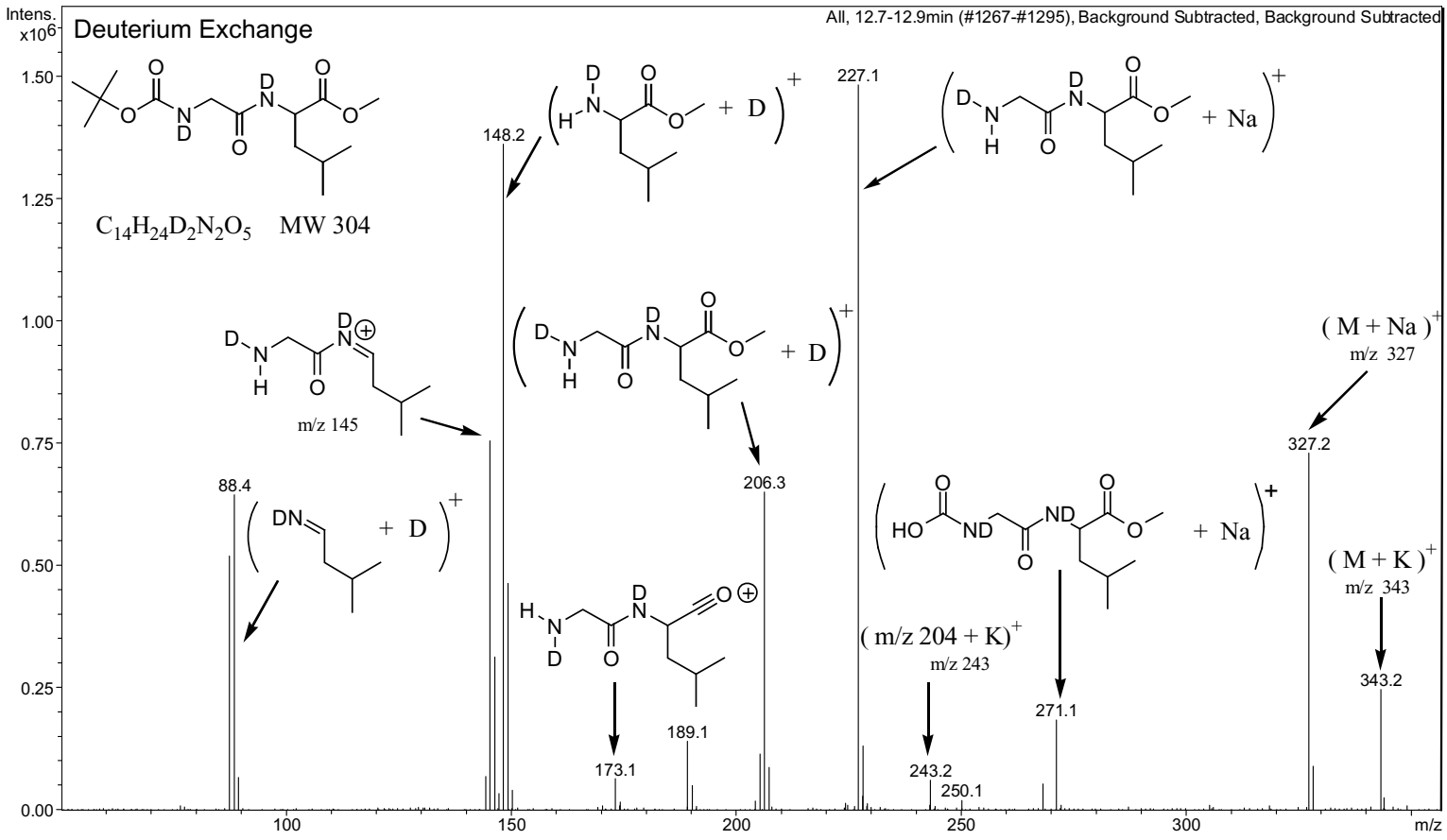

Figure 9. HPLC/CID/MS data of dipeptide 6 using a deuterated mobile phase.

the same signals as observed with the deprotected dipeptide 5, i.e., fragments at $m / z 203$ and 225. It is very well known that the $t$-Boc protection group is readily cleaved under mild acidic conditions. This often complicates the analysis of such carbamates because undesirable cleavage can occur during isolation and purification steps of $t$-Boc protected compounds or during chromatographic analysis. The coexistence of $\mathbf{5}$ and $\mathbf{6}$ could also be a consequence of incomplete derivatization $^{\circ}$ of $^{\circ}$ the ${ }^{\circ}$ unprotected ${ }^{\circ}$ dipeptide. ${ }^{\circ}$ However,${ }^{\circ}$ Figure $^{\circ} 9$ shows the prevalence of fragments at $m / z 206$ and 227 observed in the mass spectra after $\mathrm{H} / \mathrm{D}$ exchange and the low intensity of fragments exhibiting a $\mathrm{m} / \mathrm{z} 207$ and 228 , which may be attributed to H/D back exchange and ${ }^{13} \mathrm{C}$ content of the sample, provides evidence that dipeptide ${ }^{\circ} 6$ is $^{\circ}$ not $^{\circ}$ contaminated $^{\circ}$ with $^{\circ} 5$, Figure ${ }^{\circ}$.

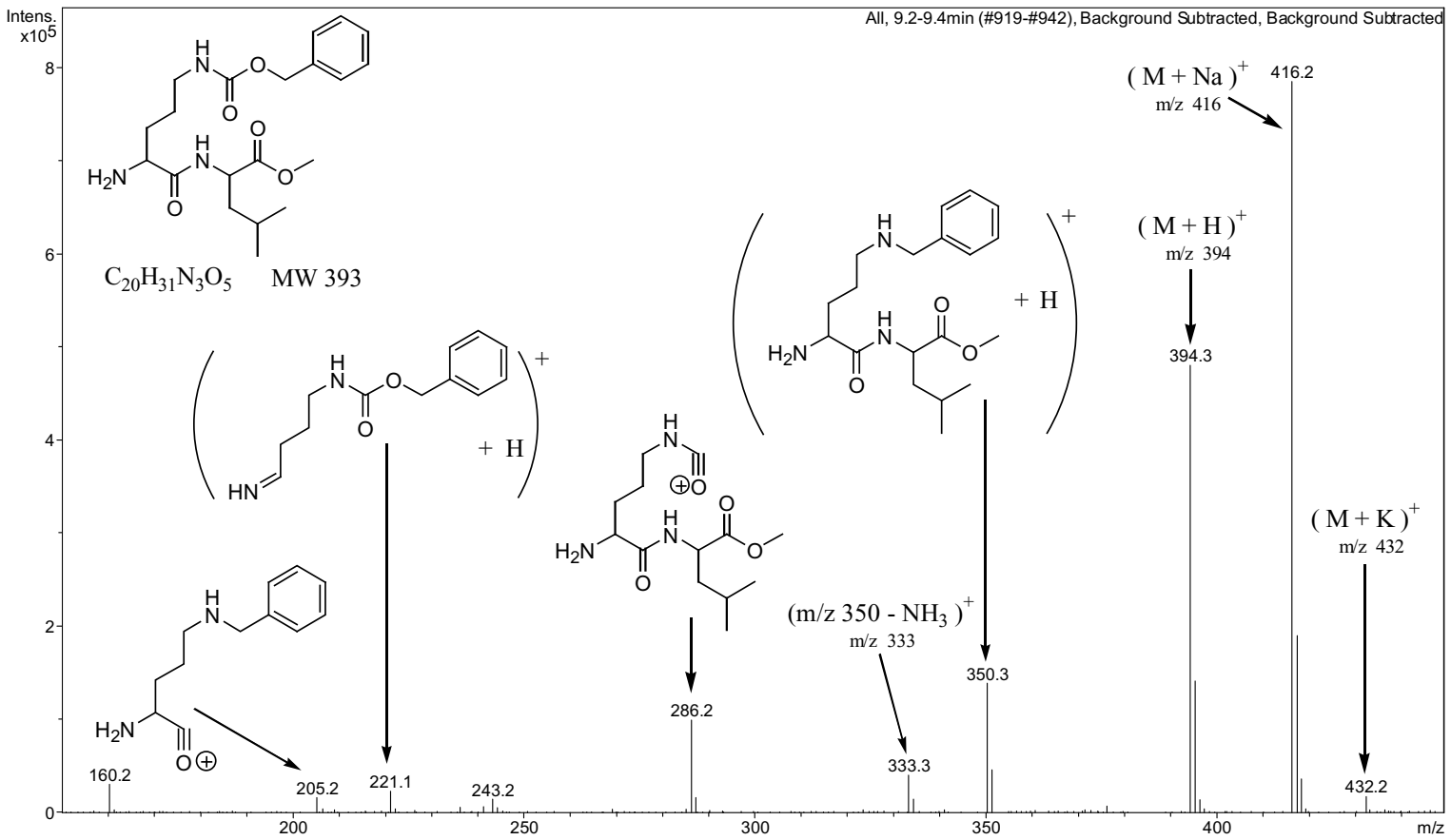

Figure 10. HPLC/CID/MS data of dipeptide 15 using a nondeuterated mobile phase. 


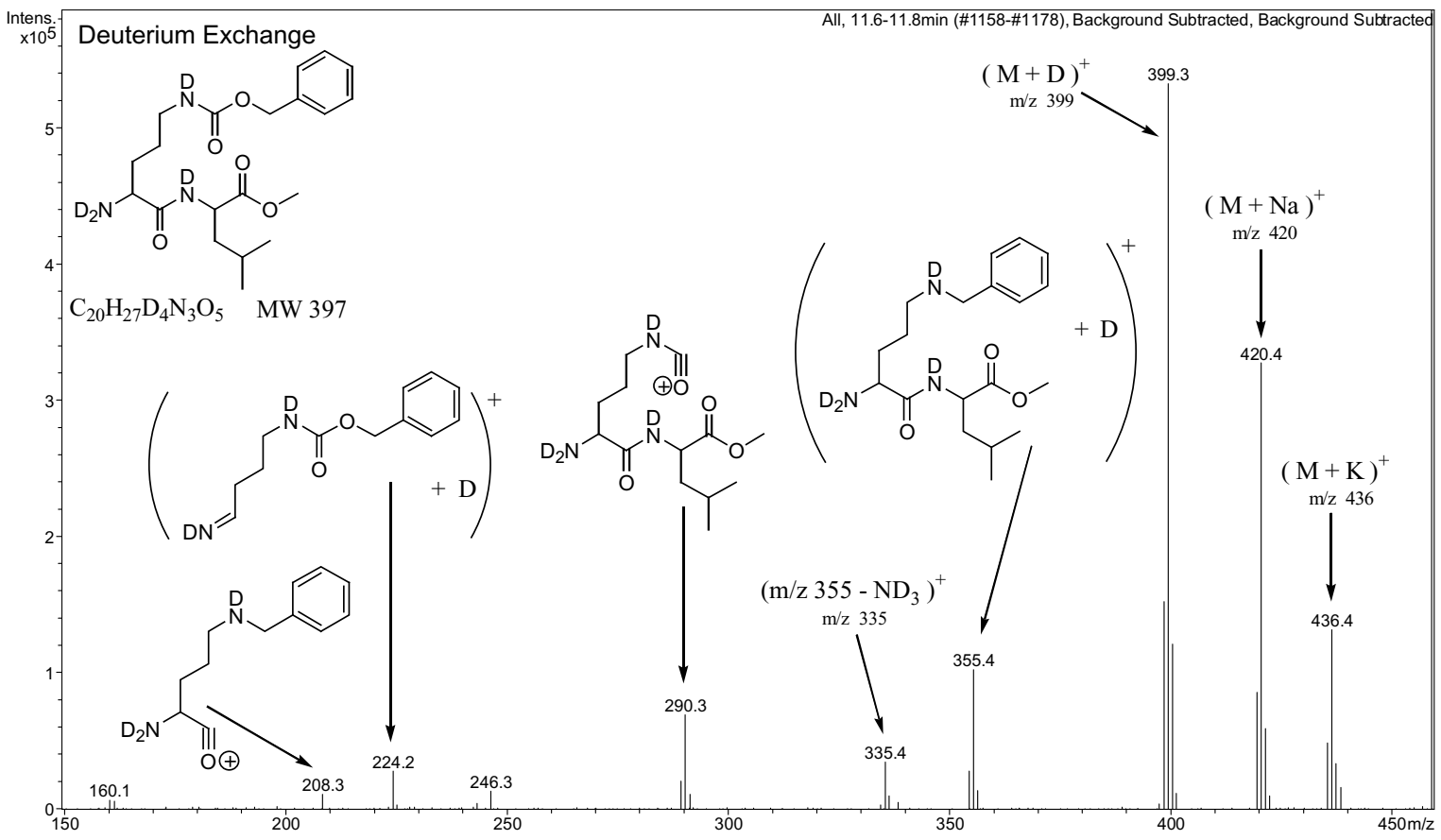

Figure 11. HPLC/CID/MS data of dipeptide 15 using a deuterated mobile phase.

Employing the on-column H/D exchange HPLC/MS methodology to Compound 15 carrying a benzyloxycarbonyl carbamate reveals the presence of four hydrogens which readily exchange in the deuterated ${ }^{\circ}$ mobile $^{\circ}$ phase, ${ }^{\circ}$ Figures $^{\circ} 10^{\circ}$ and $^{\circ} 11 .^{\circ}{ }^{\circ}$ The ${ }^{\circ}$ ions ${ }^{\circ}$ at ${ }^{\circ} \mathrm{m} / \mathrm{z}$ $394,399,416$, and 420 corresponding, respectively, to (M $+\mathrm{H})^{+},\left(\mathrm{d}_{4}-\mathrm{M}+\mathrm{D}\right)^{+},(\mathrm{M}+\mathrm{Na})^{+}$, and $\left(\mathrm{d}_{4}-\mathrm{M}+\mathrm{Na}\right)^{+}$ refer to the molecular ion of 15. Again, comparison of the MS data clearly proves the absence of a $t$-Boc group and coeluting carbamoyl impurities.

HPLC/MS analysis of the N-t-Boc protected dipeptide 16 shows three exchangeable hydrogens, one on the $t$-Boc protected amino function, one on the Z-carbamate and $^{\circ}$ one $^{\circ}$ on $^{\circ}$ the ${ }^{\circ}$ peptide $^{\circ}$ bond, $^{\circ}$ Figures $^{\circ} 12^{\circ}$ and ${ }^{\circ} 13$. Deuterated mobile phase HPLC followed by MS fragmentation of $\mathbf{1 6}$ results in incorporation of only one

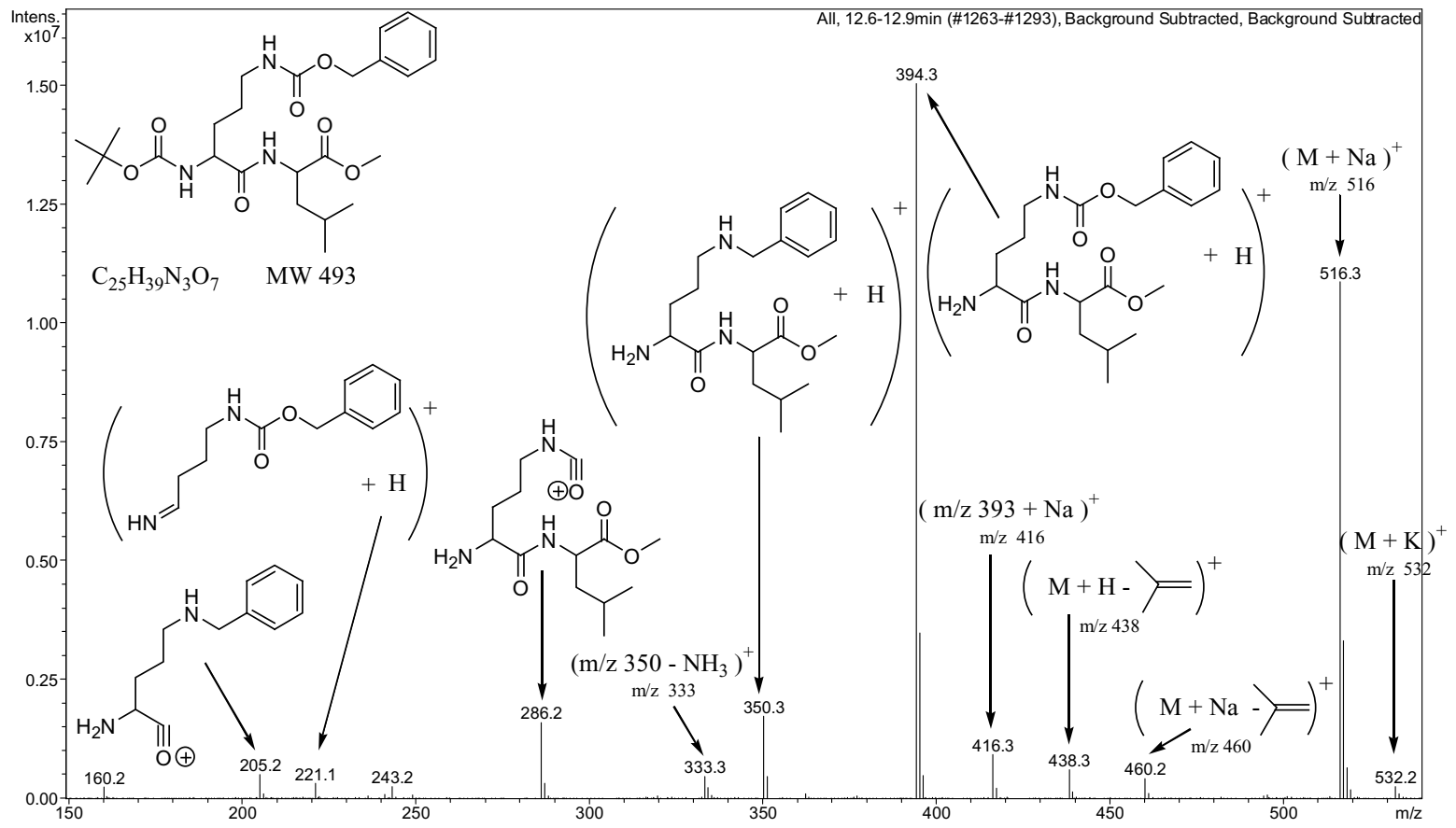

Figure 12. HPLC/CID/MS data of dipeptide $\mathbf{1 6}$ using a nondeuterated mobile phase. 


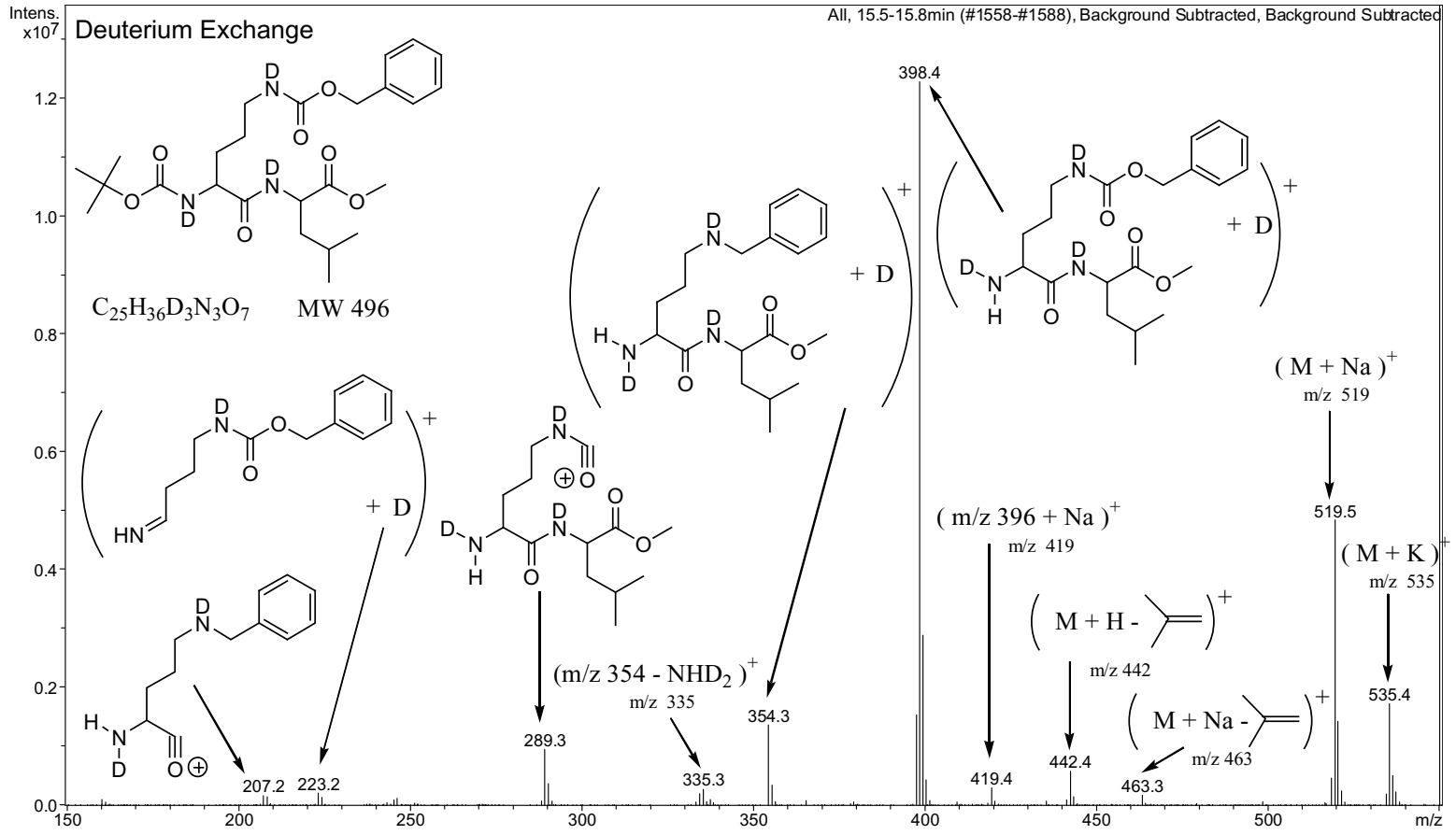

Figure 13. HPLC/CID/MS data of dipeptide $\mathbf{1 6}$ using a deuterated mobile phase.

hydrogen into the $\alpha$-amino group of the ornithine moiety. As expected, the amide bond and the Z-protected $\delta$-amino group of the ornithine moiety show exchange of one proton for deuterium. Comparison of the fragment with $\mathrm{m} / \mathrm{z} 394$ and its C-13 isotope pattern to the signal of the corresponding fragment obtained by HPLC/MS using a deuterated mobile phase exhibiting $\mathrm{m} / \mathrm{z} 398$ proves that $\mathbf{1 6}$ carries one $t$-Boc group and also allows exclusion of the presence of impurities of $\mathbf{1 5}$ in this sample. Deuterated mobile phase HPLC/MS data thus afford clear information about the purity and the presence and location of different carbamoyl protection groups of complex molecules.

Dipeptide 19 carrying a benzyl protecting group and 20, which also affords a $t$-Boc group, were also analyzed by on-column H/D exchange HPLC/MS. The spectral

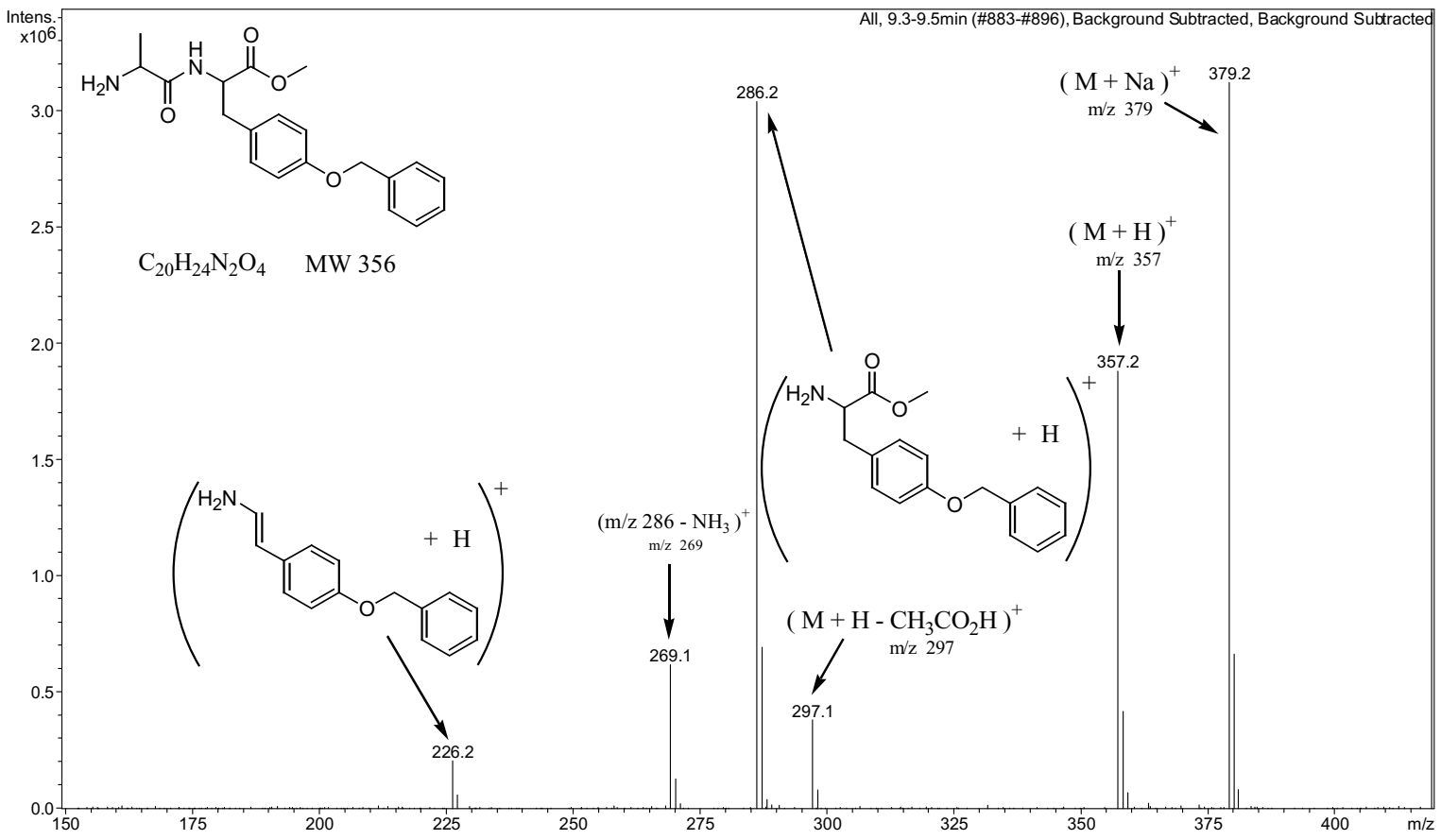

Figure 14. HPLC/CID/MS data of dipeptide 19 using a nondeuterated mobile phase. 


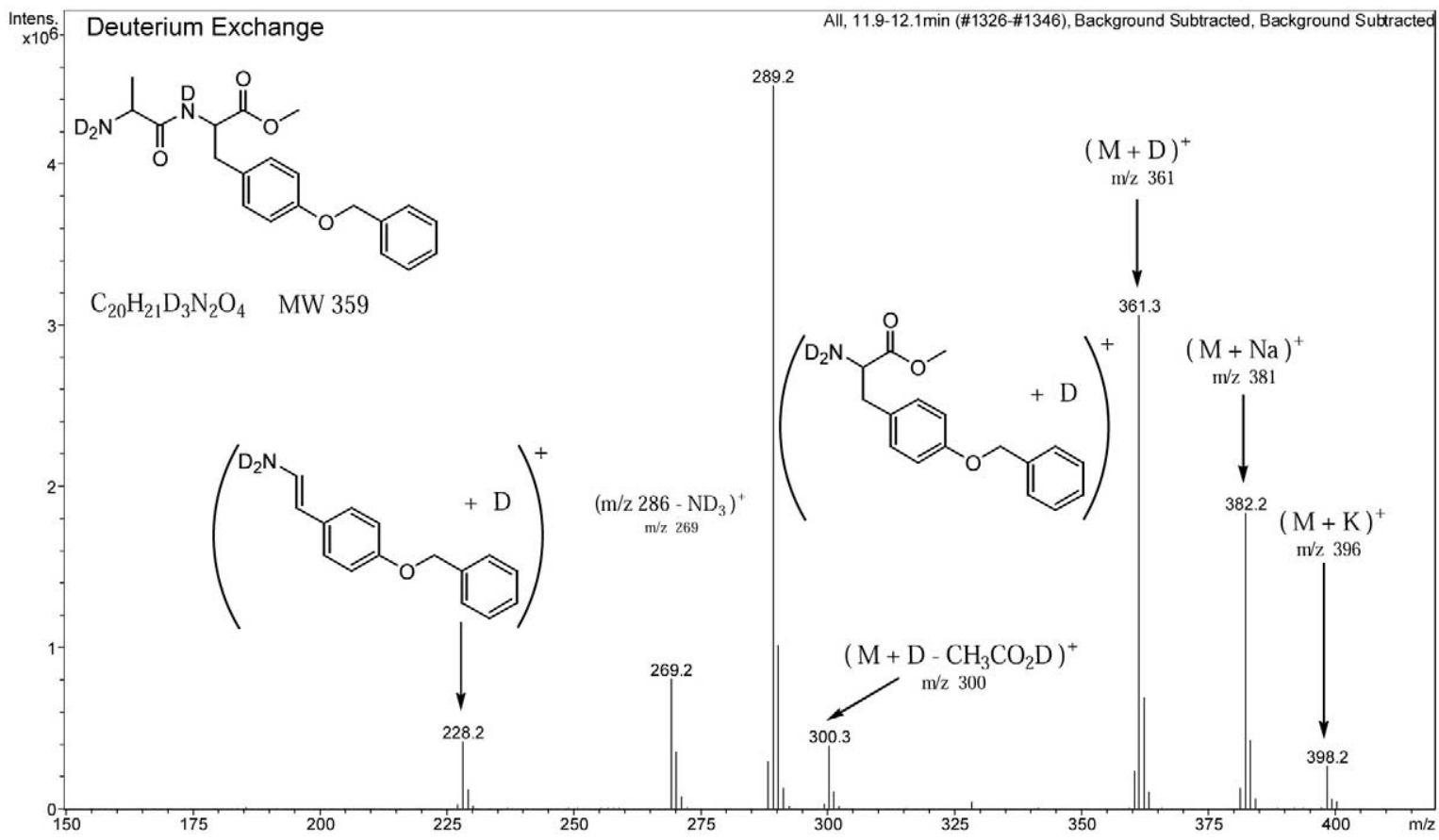

Figure 15. HPLC/CID/MS data of dipeptide 19 using a deuterated mobile phase.

MS data observed for 19 reveal three exchangeable protons and confirm the presence of the benzyl group, Figures ${ }^{\circ} 14^{\circ}$ and $^{\circ} 15 .^{\circ}$ The $^{\circ}$ location $^{\circ}$ of $^{\circ}$ the ${ }^{\circ}$ benzyl ${ }^{\circ}$ group becomes evident from the fragmentation pattern of 19 and $\mathrm{d}_{3}-\mathbf{1 9}$. The CID/MS of $\mathbf{1 9}$ shows a fragment refering to a benzylated methyl tyrosine ester (nondeuterated ion $m / z 286$, deuterated ion $m / z 289$ ) that eliminates $\mathrm{NH}_{3}$ or $\mathrm{ND}_{3}$ to give a fragment at $\mathrm{m} / \mathrm{z} 269$. The presence of this fragment ion and the H/D exchange MS data pattern reveal that the benzyl group must be attached to the phenol moiety of tyrosine but not to its amino function.

The analysis of Dipeptide 20 provides complete structural information about the presence and location of $^{\circ}$ the ${ }^{\circ}$ protecting ${ }^{\circ}$ groups, ${ }^{\circ}$ Figures $^{\circ} 16^{\circ}$ and ${ }^{\circ} 17 .^{\circ}$ Two exchangeable protons were detected and assigned to

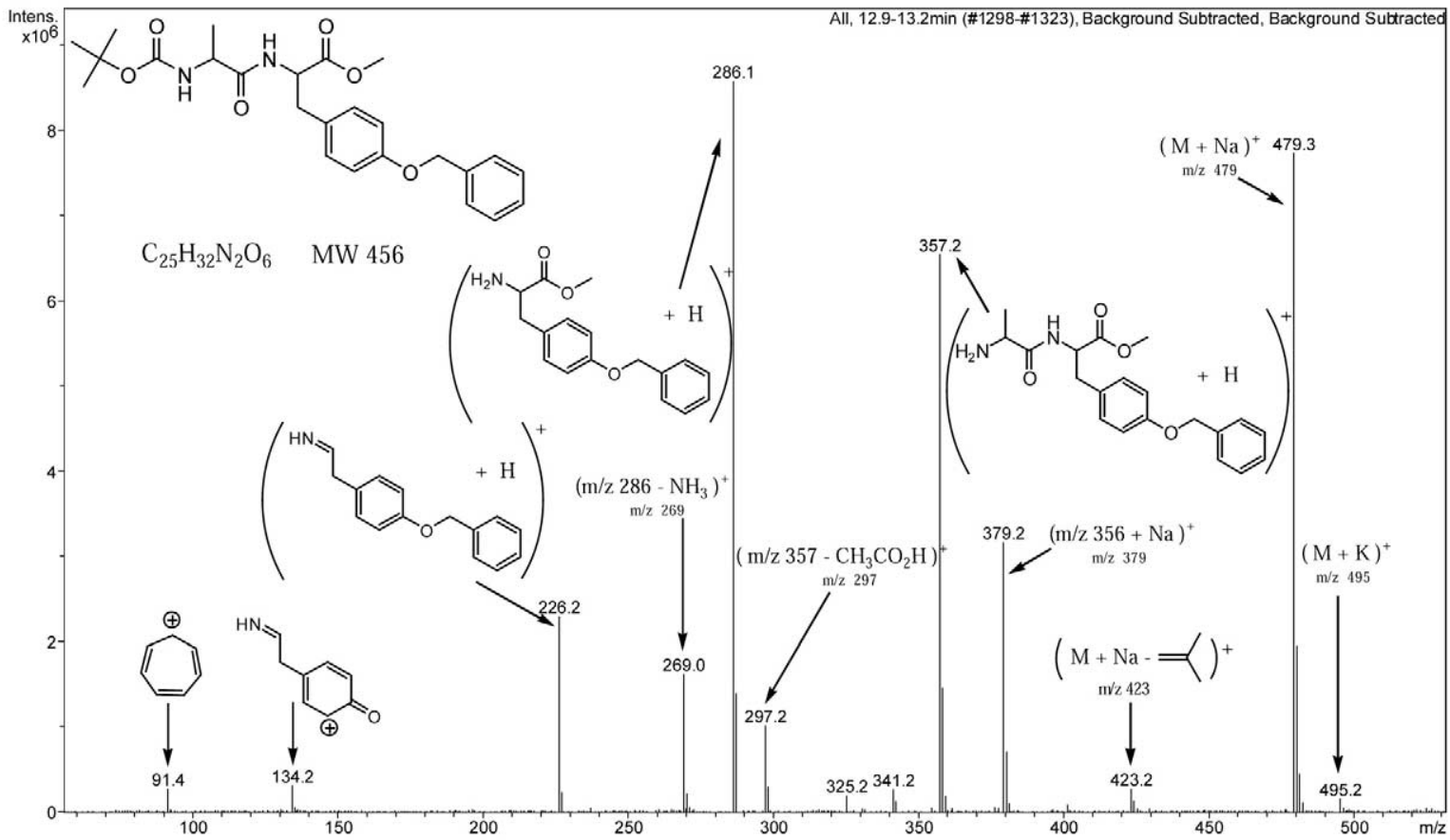

Figure 16. HPLC/CID/MS data of dipeptide 20 using a nondeuterated mobile phase. 


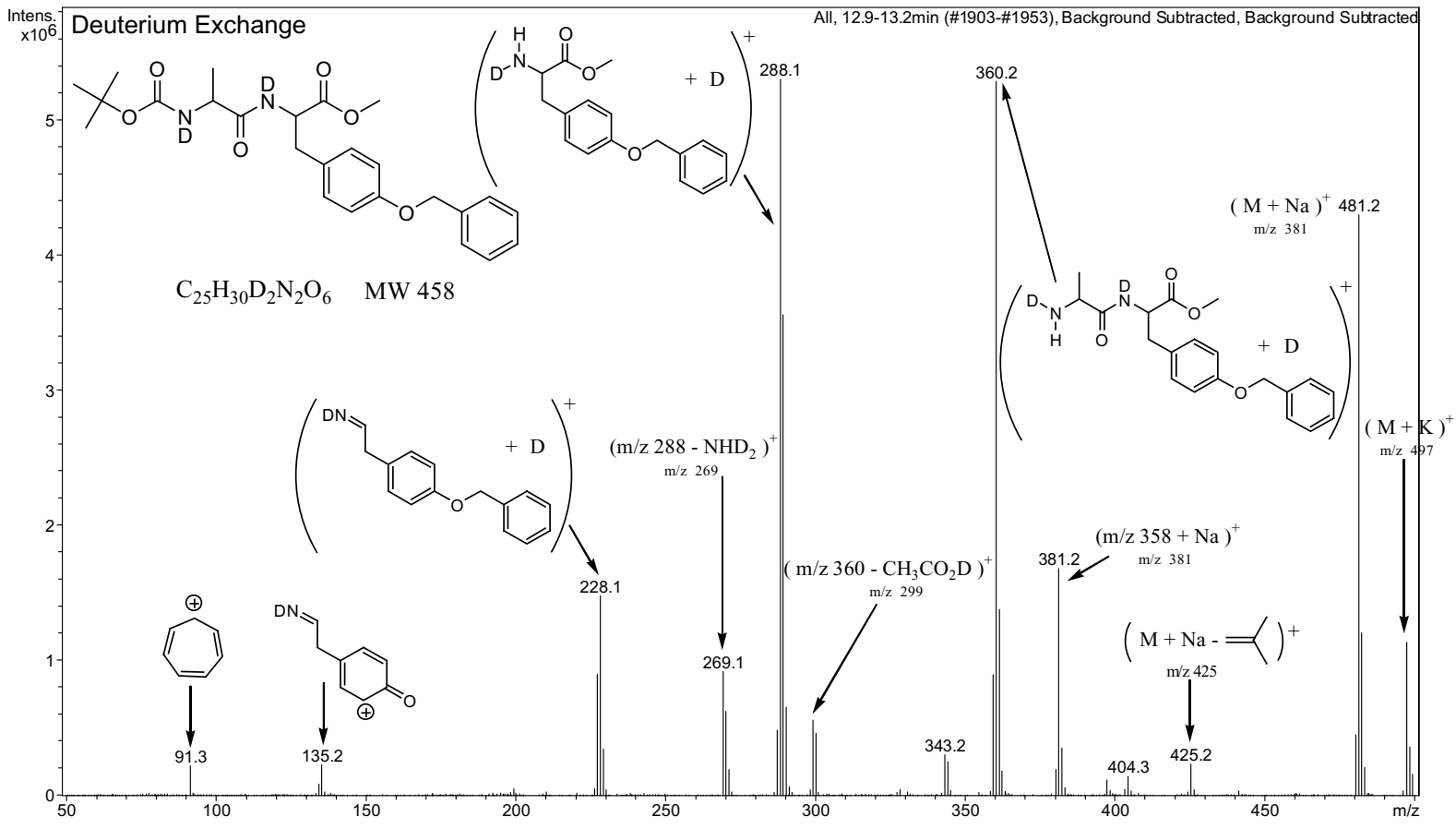

Figure 17. HPLC/CID/MS data of dipeptide 20 using a deuterated mobile phase.

protons attached to the peptide bond and one carbamate function. Again, MS data of nondeuterated $\mathbf{2 0}$ could be misinterpretated because of the intensive fragment at $\mathrm{m} / \mathrm{z} 357$ suggesting the presence of $\mathbf{1 9}$ as an impurity. This can be ruled out by comparison to the corresponding fragment obtained with deuterated 20 . The fragment ion exhibiting $\mathrm{m} / \mathrm{z} 360$ carries a hydrogen attached to a nitrogen and therefore must be assigned to a McLafferty rearrangement fragment of 20. The ion signals at $\mathrm{m} / \mathrm{z} 286$ and 357 (nondeuterated sample) and $\mathrm{m} / \mathrm{z} 288$ and 360 (deuterated sample) in conjunction with the fragment exhibiting $\mathrm{m} / \mathrm{z} 269$ reveal that the $t$-Boc group is attached to the alanine moiety at the $\mathrm{N}$-terminus. H/D Exchange MS data thus also provides a tool for differentiating between $\mathrm{N}-\mathrm{t}$-Boc-(S)-Ala-O-Bn(S)-Tyr-OMe, 20, and N-t-Boc-O-Bn-(S)-Tyr-(S)-Ala$\mathrm{OMe}$, i.e., applying this method to structure elucidation of 5-20 affords invaluable information about the amino acid sequence in addition to the presence and location of $t$-Boc protecting groups attached to these dipeptides.

On-column H/D exchange HPLC combined with mass spectrometry was also utilized for the analysis of Dipeptides 7-14, 17, and 18. In all cases, we found that this methodology greatly facilitates structure elucidation, i.e., determination of position and number of $t$-Boc protecting groups and information about the primary peptide structure. It also allows one to examine the presence or absence of coeluting impurities that exhibit the same MS spectrum using conventional HPLC/MS.

\section{Conclusions}

The usefulness of deuterated mobile phase HPLC/MS for a fast determination of the absence or presence of
$t$-Boc protection group in various amines and peptides has been demonstrated. This technique also allows for the determination of the presence of unprotected impurities that may result from undesirable carbamate cleavage under mild acidic conditions or incomplete derivatization. Employing this strategy in mass spectral structural elucidation is expected to be invaluable for routine MS analysis of complex molecules and for fast screening of combinatorial libraries that require a rapid and automated analysis of the presence and location of $t$-Boc protecting groups.

\section{Uncited References}

Per journal style, the footnote type references which you have listed in the reference list have been moved to the body text and enclosed in square brackets. They are 13,14 as explained in your author query. Any references not dealt with will be retained in this section.

\section{References}

1. McLafferty, F. W. Interpretation of Mass Spectra, 3rd ed.; University Science Books: New York, NY, 1980; pp 64-67.

2. Hunt, D. F.; McEwen, C. N.; Upham, R. A. Tetrahedron Lett. 1971, 47, 4539-4542.

3. (a) Hunt, D. F.; McEwen, C. N.; Upham, R. A. Anal. Chem. 1972, 44, 1292. (b) Sethi, S. K.; Hunt, D. F. J. Am. Chem. Soc. 1980, 102, 6953-6963. (c) Buchanan, M. V. Anal. Chem. 1982, 54, $570-574$.

4. Reed, D. R.; Kass, S. R. J. Am. Soc. Mass. Spectrom. 2001, 12, 1163-1168.

5. (a) Henion, J. D. J. Chromatogr. Sci. 1981, 19, 57-64. (b) Cairns, T.; Siegmund, E. G. Anal. Chem. 1982, 54, 2456-2461.

6. (a) McLean, T.; New, A. P.; Haskins, N. J.; Camilleri, P. J. Chem. 
Soc. Chem. Commun. 1992, 24, 1773-1775. (b) Verma, S.; Pomerantz, S. K.; McCloskey, J. Anal. Chem. 1986, 58, 2898-2902. (c) Bell, D. J.; Brightwell, M. D.; Haran, M.; Neville, W. A.; West, A. Org. Mass. Spectrom. 1991, 26, 454-457. (d) Guearini, A.; Guglielmetti, G.; Andiollo, N. Anal. Chem. 1992, 64, 204-210. (e) Zhang, Z.; Smith, D. L. Prot. Sci. 1993, 2, 522-531.

7. Bentz, B. 1.; Gayle, P. J. Int. J. Mass Spectrom. Ion Processes 1987, $78,115-130$

8. (a) Kayya, V.; Chait, B. T. Rapid Commun. Mass Spectrom. 1991, 5, 214-217. (b) Miranker, A.; Robinson, C. V.; Radford, S. E.; Aplin, R. T.; Dobson, C. M. Science 1993, 262, 896-900. (c) Johnson, R. S.; Walsh, K. A. Protein Sci. 1994, 3, 2411-2418. (d) Wagner, D. S.; Melton, L. G.; Yan, Y.; Erickson, B. W.; Anderegg, R. J. J. Prot. Sci. 1994, 3, 1305-1314. (e) Smith, D. L.;
Deng, Y.; Zhang, Z. J. Mass Spectrom. 1997, 32, 135-146. (f) Olsen, M. A.; Cummings, P. G.; Kennedy-Gabb, S.; Wagner, B. M.; Nicol, G. R.; Munson, B. Anal. Chem. 2000, 72, 5070-5078. (g) Liu, D. Q.; Hop, C. E. C. A.; Beconi, M. G.; Mao, A.; Chiu, S.-H. L. Rapid Commun. Mass Spectrom. 2001, 15, 1832-1839. (h) Lam, W.; Ramanathan, R. J. Am. Soc. Mass Spectrom. 2002, 13, 345-353.

9. Edmonds, C. G.; Pomerantz, S. C.; Hsu, F. F.; McCloskey, J. A. Anal. Chem. 1988, 60, 2314-2317.

10. Bayer, E.; Albert, K.; Nieder, M.; Grom, E.; Wolff, G.; Rindlisbacher, M. Anal. Chem. 1982, 54, 1747-1750.

11. Chen, S. S.; Kou, A. Y. J. Chromatogr. 1984, 307, 261-269.

12. Coste, J.; Le-Nguyen, D.; Castro, B. Tetrahedron Lett. 1990, 31, 205-208. 